\title{
Audit
}

\section{Liver resection for colorectal metastases}

\author{
SR Bramhall, U Gur, C Coldham, BK Gunson, AD Mayer, P McMaster, D Candinas, \\ JAC Buckels, DF Mirza
}

The Liver Unit, Queen Elizabeth Hospital, Birmingham, UK

\begin{abstract}
Background: Colorectal cancer is the second commonest malignancy in the UK. Metastases to the liver occur in greater than $50 \%$ of patients and remain the biggest determinant of outcome in these patients. Liver resection is a safe procedure that achieves good long-term survival, but surgery has traditionally been limited to select groups of patients. The improved outcome suggests that more patients could benefit from resection if more was known of what criteria are predictive of a good outcome.

Patients and Methods: A retrospective analysis was performed on all patients undergoing surgical resection of the liver for colorectal metastases between March 1989 and March 2001 in the Birmingham Liver Unit.

Results: During this period, 212 liver resections for colorectal cancer metastases were performed in 82 females and 130 males. The median follow-up was 16 months with an overall actuarial survival of $86 \%$ at 1 year, $54 \%$ at 3 years, and $28 \%$ at 5 years. The peri-operative mortality was $2.8 \%$. The number and timing (metachronous or synchronous) of metastatic lesions, the gender of the patient, pathological staging of the primary lesion or surgical resection margins had no significant influence on survival. Patients with lesions less than $5 \mathrm{~cm}$ in size had a significantly prolonged survival compared with patients with lesions greater than $5 \mathrm{~cm}$ in size $(P<0.004)$.

Conclusions: Liver resection is the only curative treatment for patients with colorectal metastases. The long-term survival reported in patients with resected colorectal metastases confined to the liver is comparable to primary surgery for solid gastrointestinal tumours. Every attempt must be made to increase the availability of liver resection to patients with hepatic metastases from colorectal cancer.
\end{abstract}

Key words: Colorectal cancer - Metastases - Liver resection - Audit

Co olorectal carcinoma is the second most common malignancy in the UK, with over 28,000 new cases per year. ${ }^{1}$ Metastases to the liver occur in more than $50 \%$ of the patients and represent the major determinant of outcome following a curative colorectal resection. Colorectal cancer is unusual among solid tumours because surgical resection of distant metastatic disease can produce long-term survival and even cure in selected patients. Hepatic resection is the only curative treatment available for patients with hepatic metastases, resulting in a 5-year survival of $30-35 \% .^{2-4}$ Only a proportion of the $10-30 \%$ of the patients with resectable liver metastases are currently referred for resection. ${ }^{2,5}$ The majority of patients are not considered suitable for resection mainly due to

Correspondence to: Mr SR Bramhall, Consultant Hepatobiliary Surgeon, The Liver Unit, Queen Elizabeth Hospital, Edgbaston, Birmingham B15 2TH, UK. Tel: +44 121627 2418; Fax: +44 121414 1833; E-mail: simon.bramhall@uhb.nhs.uk 
disseminated disease in the liver and/or concomitant extrahepatic disease. Some patients have isolated metastatic lesions which, because of their anatomical location, are regarded as technically unresectable.

Liver resection for colorectal cancer metastases has been widely reported as a safe procedure achieving good longterm survival rates, and is currently the treatment of choice for lesions confined to the liver. ${ }^{6-11}$ Despite these encouraging results, it has been suggested that performing liver resection selects tumours with 'good behaviour' and survival would be as good even if they were not resected. ${ }^{12}$ Although some patients survive for up to 2 years with liver metastases, 5-year survival without liver resection is rare. ${ }^{13-15}$ The only available treatment that can offer a costeffective cure or significantly improve long-term survival rate in these patients is surgical resection. ${ }^{16}$

We have reviewed our institutional experience of liver resections for colorectal cancer metastases to document the outcome and to determine the features of the. disease that may have a significant effect on prognosis.

\section{Patients and Methods}

Details on patients that have undergone liver resection for colorectal cancer metastases between March 1989 and March 2001 were retrieved retrospectively from the unit database (prospectively collected from September 1997) and hospital case records. Survival was calculated up until the end of March 2002.

All patients were tertiary referrals from the colorectal units in the region. The pre-operative assessment included contrast enhanced abdominal and pelvic computed tomography (CT), colonoscopy and chest Xray. Abdominal magnetic resonance imaging (MRI) and chest CT were used as second-line imaging studies to exclude the presence of extrahepatic disease. Patients were considered for resection if there was no evidence of extrahepatic disease and there was the potential for complete macroscopic resection of the tumour mass together with a margin of normal liver tissue. Patients presenting with synchronous lesions were re-imaged 3 months following their colorectal surgery prior to proceeding to liver resection.

Laparotomy was performed through a subcostal incision to confirm resectable disease and extended with a superior midline extension if resection was feasible. The liver was completely mobilised and bimanual palpation with intra-operative ultrasound scan (IOUS) was performed. Enlarged hilar lymph nodes were sent for histopathological examination by frozen section. Selected clamping of vascular structures related to the segments to be resected preceded the transection of liver parenchyma using an ultrasonic dissector. Intermittent portal venous inflow occlusion and, more recently, maintenance of low central venous pressure during hepatic transection were used to minimise the blood loss.

Complications or deaths occurring during the hospital admission or within 30 days were considered as perioperative. Complications were regarded as major if discharge was delayed or further intervention was required.

Actuarial patient survival was calculated using the Kaplan-Meier life table analysis from the time of the liver resection. Statistical analyses of potential prognostic factors were performed using the Mann Whitney U-test for continuous and Chi square test for categorical variables. Prognostic factors studied included gender, timing of metastases (synchronous versus metachronous), number and size of metastases, Dukes' staging of the primary colorectal tumour, margin clearance and width of margin clearance. The size of tumour was measured as the greatest diameter of any tumour mass. For comparison, the tumours were divided into two groups according to their sizes, smaller than $5 \mathrm{~cm}$ and equal or larger than $5 \mathrm{~cm}$.

Patients were followed-up every 3 months in the first year, 6-monthly for the following 5 years. and annually thereafter. Physical examination and blood carcinoembryonic antigen levels were used to predict the need for abdominal USS in the early part of the series and latterly CT scan. None of the patients received chemotherapy, after liver resection unless they developed recurrence during the follow-up and patients with recurrent disease were further evaluated with a view to further resectional surgery. Patients receiving chemotherapy for recurrent disease were treated according to physician and patient choice without any standard protocol being applied. Three patients during 1999 were included in a phase I study of intraportal 5-fluorouracil chemotherapy for a maximum of 7 days postoperatively.

\section{Results}

Between March 1989 and March 2001, 212 liver resections for colorectal cancer metastases were performed in 82 females and 130 males. The median age of patients was 62 years (range, 31-84 years; Table 1). Of these, 174 patients (82\%) had major hepatectomies (four segments or greater) and right hemihepatectomy (segments V-VIII inclusive) was the most common operation (Table 1). The median follow-up was 16 months (range, 0-133 months). The overall actuarial survival was $86 \%$ at 1 year, $54 \%$ at 3 years, and $28 \%$ at 5 years (Fig. 1). Six patients died in the early postoperative period, three from hepatic failure on day 7 (one patient) and day 9 (two patients), one from severe chest infection and respiratory failure on day 15, one from neutropenic sepsis and multi-organ failure on day 22 and another one from intra-abdominal bleeding 
Table 1 Patient demographics

\begin{tabular}{lccc}
\hline & $\begin{array}{c}\text { Male } \\
(n=130)\end{array}$ & $\begin{array}{c}\text { Female } \\
(n=82)\end{array}$ & $\begin{array}{c}\text { Total } \\
(n=212)\end{array}$ \\
\hline Median age in years (range) & 62 & 60 & 62 \\
$(31-84)$ & $(38-78)$ & $(31-84)$
\end{tabular}

Type of resection

$\begin{array}{lrrr}\text { Extended right hepatectomy } & 13 & 17 & 30 \\ \text { Extended left hepatectomy } & 5 & 1 & 6 \\ \text { Right hepatectomy } & 69 & 44 & 113 \\ \text { Left hepatectomy } & 14 & 11 & 25 \\ \text { Left lateral hepatectomy } & 13 & 4 & 17 \\ \quad \text { (segments II \& III) } & & & \\ \text { Segmentectomy } & 9 & 4 & 13 \\ \text { Non-anatomical resection } & 7 & 1 & 8 \\ \text { umber of metastases } & & & \\ 1 & 87 & 51 & 138 \\ 2 & 24 & 13 & 37 \\ 3 & 11 & 10 & 21 \\ 4 & 4 & 3 & 7 \\ 5 & 1 & 2 & 3 \\ 6 & 1 & 1 & 2 \\ \text { Unknown } & 2 & 2 & 4\end{array}$

Dukes' classification of primary tumour

\begin{tabular}{lrrr} 
A & 5 & 1 & 6 \\
$\mathrm{~B}$ & 30 & 25 & 55 \\
$\mathrm{C}$ & 81 & 50 & 131 \\
Unknown & 14 & 6 & 20 \\
Synchronous metastases & 28 & 23 & 51 \\
Metachronous metastases & 102 & 59 & 161 \\
\hline
\end{tabular}

and multi-organ failure on day 23. The peri-operative mortality was $2.8 \%$. Forty-five patients had complications (morbidity 22\%; Table 2). The majority of these complications were managed conservatively, only four patients required surgical intervention, two for abdominal bleeding and one each for bile leakage from the liver cut surface and biliary reconstruction for a stricture. The

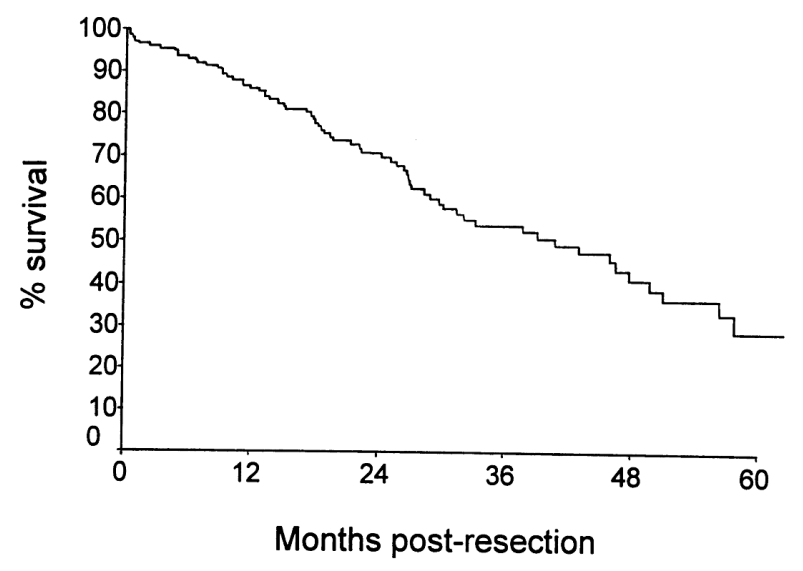

Figure 1 Overall survival (Kaplan-Meier).
Table 2 Morbidity and mortality

\begin{tabular}{|c|c|c|c|}
\hline System & Complication & $n$ & $\%$ \\
\hline \multicolumn{4}{|c|}{ Surgical - liver } \\
\hline & Acute hepatic failure & $3^{\mathrm{a}}$ & 1.4 \\
\hline & Bile duct leak & $2^{b}$ & 0.9 \\
\hline & Cut surface bile leak & $9^{c}$ & 4.2 \\
\hline & Bile duct injury & 1 & 0.5 \\
\hline & Cholangitis & 1 & 0.5 \\
\hline & Temporary jaundice & 1 & 0.5 \\
\hline & Ascites & 2 & 0.9 \\
\hline \multicolumn{4}{|c|}{ Surgical - other } \\
\hline & Wound dehiscence & 1 & 0.5 \\
\hline & Wound infection* & 4 & 1.9 \\
\hline & Bleeding & $2^{\mathrm{d}}$ & 0.9 \\
\hline & Incisional hernia & 1 & 0.5 \\
\hline & Sub-phrenic collection & 4 & 1.9 \\
\hline \multicolumn{4}{|c|}{ Respiratory } \\
\hline & Pneumothorax & 1 & 0.5 \\
\hline & Pulmonary embolism & 2 & 0.9 \\
\hline & Chest infection* & $8^{\mathrm{e}}$ & 3.8 \\
\hline & Symptomatic pleural effusion & 3 & 1.4 \\
\hline \multicolumn{4}{|l|}{ Other } \\
\hline & Renal impairment & 1 & 0.5 \\
\hline & Cardiac dysrhythmia* & 3 & 1.4 \\
\hline & Cerebrovascular accident & 1 & 0.5 \\
\hline & Line sepsis* & 1 & 0.5 \\
\hline & Deep venous thrombosis & 1 & 0.5 \\
\hline & Neutropenic sepsis & $1^{\mathrm{f}}$ & 0.5 \\
\hline \multicolumn{2}{|c|}{ Overall number of patients } & 45 & 22 \\
\hline
\end{tabular}

${ }^{*}$ Minor morbidity $7.5 \%$.

${ }^{\mathrm{a}}$ All 3 of these patients died.

${ }^{b}$ One of these patients required surgery.

'One of these patients required surgery.

${ }^{\mathrm{d}}$ Both of these patients required surgery and one died of multiorgan failure following intra-abdominal bleeding.

${ }^{\mathrm{e} O n e}$ of these patients died of a severe chest infection and respiratory failure.

fThis patient died following immediate postoperative intraportal chemotherapy as part of a phase II clinical trial.

median hospital stay was 8 days and has decreased to 7 days in the last 2 years of the study period. A median of 2 units of blood was used (range, 0-35 units) and 71 (33\%) resections were performed without any blood transfusion. Analysis of the proposed prognostic factors revealed the following.

\section{Number of metastatic lesions}

Patients with solitary metastatic lesions $(n=138)$ had a 3year survival of $58 \%$ and patients with multiple lesions $(n$ $=70)$ had a 3 -year survival of $48 \%(P=0.16)$. The total number of metastases (Table 1) in the group with multiple lesions did not appear to make a significant difference to survival. 


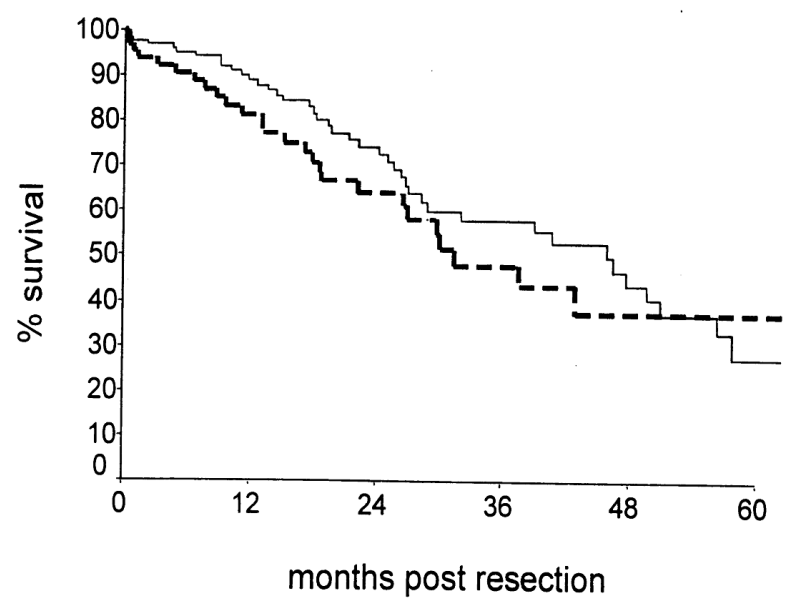

Figure 2 Survival in patients with lesions $>5 \mathrm{~cm}$ (solid line) versus those patients with lesions $<5 \mathrm{~cm}$ (dotted line; $P=0.004$; Kaplan-Meier).

\section{Timing of metastasis}

There was no significant difference in survival between patients with metachronous lesions ( $n=161$; 3-year survival, $55 \%)$ and synchronous lesions $(n=51$; 3-year survival, $52 \% ; P=0.7)$.

\section{Size of lesions}

There was a significant difference in survival between patients who had tumours smaller than $5 \mathrm{~cm}(n=83$; 3year survival, 67\%) and patients with tumours either equal to or larger than $5 \mathrm{~cm}(n=108$; 3-year survival, $44 \%$; $P=0.004$; (Fig 2).

\section{Pathological staging of the primary tumour}

The primary colorectal tumours were classified as Dukes' stage A $(n=6), \mathrm{B}(n=55)$, and C $(n=131 ;$ Table 1$)$. The details of the primary colorectal tumour were missing in 20 patients and these were excluded from statistical analysis. There was no significant survival difference between the Dukes' stage. Patients with Dukes' A and B primary tumours did not have a significantly better survival than patients with Dukes' $C$ tumours (3-year survival $58 \%$ and $48 \%$, respectively; $P=0.13$ ).

\section{Resection margins}

Macroscopic clear margins were achieved in all resections. Histopathological evaluation, however, revealed microscopic margin involvement in 22 patients. Resection margins were not specifically mentioned in the pathology reports of 30 patients (early in the series) and 160 patients had clear margins. The patients with involved margins had a 3-year survival of $41 \%$ and the patients with non-involved margins had a 3-year survival of $56 \%(P=0.6)$. Patients with a histopathological margin clearance of $0.5-4 \mathrm{~mm}(n=48)$ had a 3-year survival of $67 \%$, patients with a clearance of 5-9 mm $(n=26)$ had a 3-year survival of 39\%, and patients with a clearance margin of $10 \mathrm{~mm}$ or greater $(n=105)$ had a 3 -year survival of $56 \%$. These differences did not achieve statistical significance $(P=0.45)$.

\section{Gender}

There was no significant survival difference between male and female patients; the 3-year survival was 52\% and $58 \%$, respectively $(P=0.8)$.

\section{Discussion}

Our own lack of understanding of the clinical and pathological behaviour of metastatic disease and the sensitivity of current imaging modalities mean that not all patients benefit from resection and patient selection remains the most challenging issue. ${ }^{17}$ There have been numerous prognostic factors reported but only a few are routinely used. Fong et al. ${ }^{18}$ reported on 1001 liver resections for metastatic colorectal cancer and identified seven independent predictors of poor long-term outcome. These were positive resection margins, extrahepatic disease, lymph node positive, lymph node positive primary disease, a disease-free interval between primary and metastases of less than 12 months, greater than one liver metastasis, largest metastasis of greater than $5 \mathrm{~cm}$ and a carcino-embryonic antigen level of greater than 200 $\mathrm{ng} / \mathrm{ml}$. These were then combined into a scoring system where each of the above was scored with one point; any patient scoring greater than or equal to five did not survive long-term. ${ }^{18}$

This study represents one of the largest UK experiences of liver resection for colorectal metastases and the results have shown that only the size of metastatic lesions had a significant effect on long-term survival but the numbers reported are significantly less than in the study by Fong et al. ${ }^{18}$ Patients with lesions less than $5 \mathrm{~cm}$ in size had a survival advantage over those patients with larger lesions. These patients, however, still had a survival benefit following liver resection that is impossible to quantify but is probably better than can be offered by any other treatment modality. Scheele et al. ${ }^{7}$ also reported inferior survival rates for tumours larger than $5 \mathrm{~cm}$; however, other recent studies, ${ }^{19,20}$ found no difference in long-term survival between small $(\leq 5 \mathrm{~cm})$ and large $(>5 \mathrm{~cm})$ tumours.

Four and more metastatic lesions have been commonly regarded as exclusion criteria in patient selection..$^{6,8,21,22} \mathrm{~A}$ 
number of recent studies have failed to support this view. ${ }^{7,23}$ Although an increased number of lesions can decrease the resectability rate. all patients with technically resectable lesions should be considered for resection. In these data, only 9 patients with greater than four lesions underwent resection; these were in the latter part of the series and a greater number of patients are now being considered for, and offered, resection with more than four lesions.

Involved resection margins have been reported as an indicator of poor prognosis in previous studies. $6,8,11,24$ Although obtaining a clear margin of more than $1 \mathrm{~cm}$ has been suggested as mandatory ${ }^{21}$ and this should be the surgical goal in all liver resections, these data do not support this hypothesis. In this series, there were 22 patients with microscopic involvement of resection margins, 6 of whom had large ( $>6 \mathrm{~cm}$ solitary lesions and there was no significant survival difference between patients with involved margins and those with non-involved margins. The longest survivor in the series, who is still alive after 12 years, had microscopic involvement of the margins. The accuracy of this statistical comparison is, however, questionable because of the small number of patients. This study also failed to show a correlation between the width of margin clearance and long-term survival although the numbers are again small. Yamamoto et al. ${ }^{19,25}$ have reported that they were unable to identify microscopic satellite deposits in the parenchyma more than $10 \mathrm{~mm}$ from the metastatic tumours; therefore, it is difficult to justify attempting to obtain a surgical margin of more than $10 \mathrm{~mm}$ on oncological grounds. We, therefore, believe that the inability to obtain a clear margin of $10 \mathrm{~mm}$ should not exclude a liver resection. If the resection margins are believed to be involved, ablation of the margins could be combined with liver resection although survival data using this approach are awaited..$^{18,26}$

A more favourable outcome of liver resection in patients with early stage primary colorectal tumours has been reported. ${ }^{67,23,27}$ Two large series of liver resection for patients with colorectal cancer metastases have shown that patients with Dukes' B primary tumours had a significantly better survival than patients with Dukes' C tumours; both however, concluded that the survival for patients with Dukes' stage C primary tumours was significantly improved by liver resections. ${ }^{6,7}$ These data and some recent studies have failed to confirm the effect of stage of primary colorectal cancer on long-term survival. ${ }^{8,9,20}$ The increasing number of patients being offered a liver resection and longer follow-up will allow these questions to be answered in the future.

A long metastases-free interval after resection of the colorectal primary tumour has been reported as an important prognostic factor related to a more favourable tumour biology. ${ }^{6-8,11,28}$ The presence of synchronous metastases, however, was not found sufficient to exclude patients from hepatic resections in any of these series. These data and a number of other studies have failed to support this finding with no significant survival advantage being observed in patients with metachronous lesions compared to synchronous lesions. ${ }^{9,19,20,23}$ Our own practice of re-imaging 3 months following the initial colorectal resection might influence these data. ${ }^{29}$

Liver resection is still the only curative treatment for selected patients with colorectal metastases. The longterm survival reported in a selected group of patients with resected colorectal metastases confined to the liver is comparable to, and in many cases better than, primary surgery for solid gastrointestinal tumours. Every attempt must be made to increase the availability of liver resection to patients with hepatic metastases from colorectal cancer. The greatest short-term impact on survival in patients with colorectal metastases is the identification of resectable lesions, which requires a more pro-active approach in the follow-up of patients after colorectal resection. Our own unit has seen an exponential increase in referrals of patients with metastases and this increase should be encouraged and cultivated. The resectability rate of colorectal metastases to the liver also needs to be increased and patients with initially unresectable lesions should be considered for chemotherapy and re-assessed for resection following treatment. ${ }^{30,31}$ The high recurrence rates (approximately 70\%) following liver resection suggest that effective adjuvant therapy is also needed and this necessitates the inclusion of patients in randomised clinical trials. The intensive monitoring of patients following liver resection will also allow the detection of the small group of patients who can safely undergo a reresection of liver metastases that will also have a 5-year survival of more than $25 \% .^{32-34}$ The development of multimodality treatment strategies relies on the cooperation of surgeons. oncologists, radiologists and the establishment of extensive teams of professions allied to medicine.

\section{References}

1. OPCS. Mortality Statistics - Cause. Report No. DH2 no. 19. London: HMSO, 1992.

2. Sugihara K, Yamamoto J. Surgical treatment of colorectal liver metastases. Ann Chir Gynaecol 2000; 89: 221-4.

3. Martin LW, Warren RS. Current management of colorectal liver metastases. Surg Oncol Clin North Am 2000; 9: 853-76, discussion 877-8.

4. Fong Y. Surgical therapy of hepatic colorectal metastasis. CA Cancer J Clin 1999; 49: 231-55.

5. Fong Y, Cohen AM, Fortner JG, Enker WE, Turnbull AD, Coit DG et al. Liver resection for colorectal metastases. J Clin Oncol 1997; 15: 938-46.

6. Hughes KS, Simon R, Songhorabodi S, Adson MA, Ilstrup DM, Fortner JG et al. Resection of the liver for colorectal carcinoma metastases: a multi-institutional study of patterns of recurrence. Surgery 1986; 100: 278-84. 
7. Scheele J, Stang R, Altendorf-Hofmann A, Paul M. Resection of colorectal liver metastases. World J Surg 1995; 19: 59-71.

8. Gayowski TJ, Iwatsuki S, Madariaga JR, Selby R, Todo S, Irish W et al. Experience in hepatic resection for metastatic colorectal cancer: analysis of clinical and pathologic risk factors. Surgery 1994; 116: 703-10.

9. Taylor M, Forster J, Langer B, Taylor BR, Greig PD, Mahut C. A study of prognostic factors for hepatic resection for colorectal metastases. Am J Surg 1997; 173: 467-71.

10. Holm A, Bradley E, Aldrete JS. Hepatic resection of metastasis from colorectal carcinoma. Morbidity, mortality, and pattern of recurrence. Ann Surg 1989; 209: 428-34.

11. Scheele J, Stangl R, Altendorf-Hofmann A, Gall FP. Indicators of prognosis after hepatic resection for colorectal secondaries. Surgery 1991; 110: 13-29.

12. Fong Y, Kemeny N, Paty P, Blumgart LH, Cohen AM. Treatment of colorectal cancer: hepatic metastasis. Semin Surg Oncol 1996; 12: 219-52.

13. Wagner JS, Adson MA, Van Heerden JA, Adson MH, Ilstrup DM. The natural history of hepatic metastases from colorectal cancer. A comparison with resective treatment. Ann Surg 1984; 199: 502-8.

14. Wanebo HJ, Semoglou C, Attiyeh F, Stearns MJ. Surgical management of patients with primary operable colorectal cancer and synchronous liver metastases. Am J Surg 1978; 135: 81-5.

15. Wilson SM, Adson MA. Surgical treatment of hepatic metastases from colorectal cancers. Arch Surg 1976; 111: 330-4.

16. Beard SM, Holmes M, Price C, Majeed AW. Hepatic resection for colorectal liver metastases: a cost-effectiveness analysis. Ann Surg 2000; 232: 763-76.

17. Valls C, Andia E, Sanchez A, Guma A, Figueras J, Torras J et al. Hepatic metastases from colorectal cancer: pre-operative detection and assessment of resectability with helical CT. Radiology 2001; 218: 55-60.

18. Fong Y, Fortner J, Sun RL, Brennan MF, Blumgart LH. Clinical score for predicting recurrence after hepatic resection for metastatic colorectal cancer: analysis of 1001 consecutive cases. Ann Surg 1999; 230: 309-18.

19. Yamamoto J, Shimada K, Kosuge T, Yamasaki S, Sakamoto M, Fukuda $\mathrm{H}$. Factors influencing survival of patients undergoing hepatectomy for colorectal metastases. Br J Surg 1999; 86: 332-7.

20. Bakalakos EA, Kim JA, Young DC, Martin EW. Determinants of survival following hepatic resection for metastatic colorectal cancer. World J Surg 1998; 22: 399-404.

21. Ballantyne GH, Quin J. Surgical treatment of liver metastases in patients with colorectal cancer. Cancer 1993; 71 (Suppl. 12): 4252-66.
22. Greenway B. Hepatic metastases from colorectal cancer: resection or not. Br J Surg 1988; 75: 513-9.

23. Jaeck D, Bachellier P, Guiguet M, Boudjema K, Vaillant JC, Balladur P et al. Long-term survival following resection of colorectal hepatic metastases. Association Française de Chirurgie. Br J Surg 1997; 84: 977-80.

24. Weber SM, Jarnagin WR, DeMatteo RP, Blumgart LH, Fong Y. Survival after resection of multiple hepatic colorectal metastases. Ann Surg Oncol 2000; 7: 643-50.

25. Yamamoto J, Sugihara K, Kosuge T, Takayama T, Shimada K, Yamasaki S et al. Pathologic support for limited hepatectomy in the treatment of liver metastases from colorectal cancer. Ann Surg 1995; 221: 74-8.

26. Dwerryhouse SJ, Seifert JK, McCall JL, Iqbal J, Ross WB, Morris DL. Hepatic resection with cryotherapy to involved or inadequate resection margin (edge freeze) for metastases from colorectal cancer. Br J Surg 1998; 85: 185-7.

27. Hughes KS, Rosenstein RB, Songhorabodi S, Adson MA, Ilstrup DM, Fortner JG et al. Resection of the liver for colorectal carcinoma metastases. A multi-institutional study of long-term survivors. Dis Colon Rectum 1988; 31: 1-4.

28. Sugihara K, Hojo K, Moriya Y, Yamasaki S, Kosuge T, Takayama T. Pattern of recurrence after hepatic resection for colorectal metastases. Br J Surg 1993; 80: 1032-5.

29. Lambert LA, Colacchio TA, Barth RJ. Interval hepatic resection of colorectal metastases improves patient selection. Arch Surg 2000; 135: 473-9.

30. Bismuth H, Adam R, Levi F, Farabos C, Waechter F, Castaing D et al. Resection of non-resectable liver metastases from colorectal cancer alter neoadjuvant chemotherapy. Ann Surg 1996; 224: 509-20.

31. Gil-Delgado MA, Guinet F, Castaing D, Adam R, Coeffic D, Durrani AK et al. Prospective phase II trial of iriontecan, 5-fluorouracil, and leucovorin in combination as salvage therapy for advanced colorectal cancer. Am J Clin Oncol 2001; 24: 101-5.

32. Imamura H, Kawasaki S, Miyagawa S, Ikegami T, Kitamura H, Shimada R. Aggressive surgical approach to recurrent tumors after hepatectomy for metastatic spread of colorectal cancer to the liver. Surgery 2000; 127: 528-35.

33. Yamamoto J, Kosuge T, Shimada K, Yamasaki S, Moriya Y, Sugihara K. Repeat liver resection for recurrent colorectal liver metastases. Am J Surg 1999; 178: 275-81.

34. Adam R, Bismuth H, Castaing D. Waechter F, Navarro F, Abaseal A et al. Repeat hepatectomy for colorectal liver metastases. Ann Surg 1997; 225: 51-60, discussion 60-2 